\section{Pesquisa anatômica sobre a ramificação e a disposição das artérias e veias da placenta de bovinos azebuados}

\author{
Patterns of branching of the placental vessels in zebu bovines
}

Silvia Ferreira CARAMBSLLA'; Althen 'Teixeira FILHO'; Maria Angelica MICIINO; Liberato J. A. DII)IO'; Wilson Machado de SOUZA ${ }^{+}$

\author{
CORRESPONDENCETO \\ Maria Angélica Miglino \\ Departamento de Cirurgia \\ Faculdade de Medicina \\ Veterinária e Zootecnia da USP \\ Av. Prof. Dr. Orlando Marques \\ de Paiva, 87 - Cidade \\ Universitária Armando de Salles \\ Oliveira - 05508-900 - São Paulo \\ SP - Brasil \\ e-mail:miglino@usp.br \\ 1 - Universidade Federal de \\ Pelotas - UFPel - RS \\ 2 - Departamento de Cirurgia \\ Faculdade de Medicina Veterinária \\ e Zootecnia da USP - SP \\ 3 - Departamento de Mortologia \\ Escola Paulista de Medicina - \\ UNIFESP, São Paulo, SP \\ Universidade de Santo Amaro \\ São Paulo, $S P$ \\ 4 - Universidade Estadual \\ Paulista - UNESP. Araçaluba, SP
}

\title{
RESUMO
}

A ramificação e a disposição das artérias e veias placentárias foram estudadas em 20 vacas da raça Nelore. Uma anastomose entre as duas artérias do funiculo umbilical aparece em $75 \%$ dos casos (70\% única e $5 \%$ dupla). Os tipos de distribuição vásculo-cotiledonário foram baseados nos arranjos das artérias e veias nas suas relações com os cotilédones. Um cotilédone suprido por uma única artéria é drenado por múltiplas veias e, em poucos casos, as artérias e veias suprem e drenam 'espectivamente cotilédones dos cornos uterinos gestante e não gestante.

JNITERM( )S: Placenta; Artérias; Veias; Bovinos

\section{INTRODUÇ̃̃O}

$\square$ ssa pesquisa anatomica tem por objetivo obter dados sobre os aspectos morfológicos da disposição e da ramilicaçaio das artérias e velas da placenta em bovinos rzebuados. A !́m disso, procuramos comparar nossos achados com ide Miglino ${ }^{15}(1991)$ em bovinos I lolstein e llereford.

\section{MATERIAL E MÉTODO}

Para a realização deste trabaiho utilizamos as placentas de acas gestantes, azcbuadas, em diversos estágios de prenher. Jeterminamos o tempo de gestação de 10 dos 20 animais pela nensuraçào do comprimento do feto, de acordo com a tabela de 2oberts ${ }^{20}(1986)$.

Retiramos de cada animal o útero com seu conteúdo, poucos ninutos após o abale e abertura da cavidade abdominal, inci-sando I seguir o útero.

As peças eram lavadas com água morna, ao mesmo tempo :m que eram massageardass suavemente em direção à extremidade eeccionada do funículo umbilical, com o propósito de eliminar o angue residual. Após este procedimento, colocávamos uma cânula :m cada um dos vasos do funiculo umbilical e injetávamos látex veoprene 650 ( Du Pont) corado com pigmento especílico (Suvinil, Slasurit do Brasil l.dda.) em quatro tonalidades de cor.

A fixaçào e a conservação das placentas foi feita com ;olteção acyosa de formol a $10 \%$ durante 48 horas no mínimo. Nessa ztapa, tomamos os cuidados necessários para distender as peças de forma conveniente à posterior realização da dissecação e documentação. A dissecaçào ló iniciada pela individualização dos vasos do funículo umbilical, retirando-se primeiramente a membrana cório-alantóide e, posteriormente, a getatina de Wharton que se dispõe no seu trajeto.

De cada caso fizemos um desenho da anastomose arterial do funículo umbilical e da distribuiçio das artérias e outro da distribuição das veias, esquematizando os cotilédones pequenos, médios e grandes. Os casos considerados mais interessantes foram fotografados e alguns ilustram este trabalho.

\section{RESULTADOS}

Nossos resultados serão apresentados na seguinte ordem:

I - Vasos do funiculo umbilical

II - Hilo da placenta

III - Placenta

\section{I - VASOS DO FUNICULO UMBILICAI}

Os vasos umbilicais foram contados em número de $4 \mathrm{em}$ todos os 20 casos examinados, sendo 2 artérias e 2 veias. $\Lambda$ s veias ocupavam posição periférica c as artérias dispunham-se centralmente, com o úraco localizado em situação mediana (ligg. $1)$.

Uma anastomose inter-arterial ocorreu em 15 casos sobre 20, ou seja, em 75\% 9,7 (Fig. 1). Esta anastomose era única em 14 casos sobre 20 , ou seja, 70\%, 9,7 , sendo que em um caso, $5,0 \%$ $\pm 4,9$, era dupla. 
A disposição da anastomose inter-arterial era variada (Fig. 2), ou scja, quando única se apresentava em "V" (6 casos sobre 20 , ou seja, 30,0\%+10,3), transversal (6 sobre 20 , ou seja, 30\% 10,3$)$, obliqua ( 1 caso sobre 20, ou seja, 5,0\% $\pm 4,9$ ), e em "H" ( 1 caso sobre 20, ou seja, 5, $(0 \%, 4,9)$. Quando dupla, as comunicações inter-arteriais eram transversal e em "V" ( 1 caso sobre 20 , ou seja, $5,(0 \%) \pm 4,9)$.

()sesquemas que se seguem ma Pranchá I (Fig. 8) demonstram os casos em que foram verificadas anastomoses inter-arteriais.

()s vasos cordonais são os que se originam no funiculo umbilical e que se distribuem no funiculo e na placenta. Os primeiros constituem o vasa vasoram, cujo estudo não foi incluido nesta investigação. (Os vasos cordonais destinados à placenta têm origem na anastomose inter-arterial e dirigem-se a placenta, mais precisamente aos cotilédones placentários. Somente num único caso (5.) $\pm 4,9)$. um vaso cordonal dirigia-se para a porção intercotiledonária.

Dos 15 casos sobre $20 \mathrm{em}$ que ocorreram anastomoses interarteriais. 12 casos $(60,0 \% \pm 10.7)$ apresentaram vasos cordonais (Fig. 1). Estes eram únicos em 10 casos sobre $20(50,0 \% \pm 11,2) \mathrm{e}$ duplos em 2 casos sobre $20(10,0 \% \pm 6,7)$.

()s ramos cordonais nutrem os cotilédones placentários e portanto são considerados ramos cordonais cotiledonários. Eles dirigem-se a $1(30,0 \% \pm 10,3), 2(15,0 \pm 8,0)$ e $4(5,0 \% \pm 4,9)$ cotilédones placentários. Num caso isolado $(5,0 \pm 4,9)$, os dois ramos cordonais supriam cinco cotilédones.

\section{II - IIII.() I) $\triangle P I . \wedge($ PNTA}

() hilo da placenta é a área de implantação do funículo umbilical ou pediculo na superficie fetal da placenta, semelhante ao que ocorre, em geral, com os pediculos vasculares de alguns órgàos. A área hilar tinha de 10 a $12 \mathrm{~cm}$ de diânetro e estava situada no centro da placenta, em uma região que se caracterizava pela presença de um grande número de cotilédones mais desenvolvidos (Figs. 3 e 4 )

Os cotilídones dispunham-se em 4 fileiras, 2 de cada lado da implantaçào do pedículo umbilical no hilo da placenta (Fig. 4).
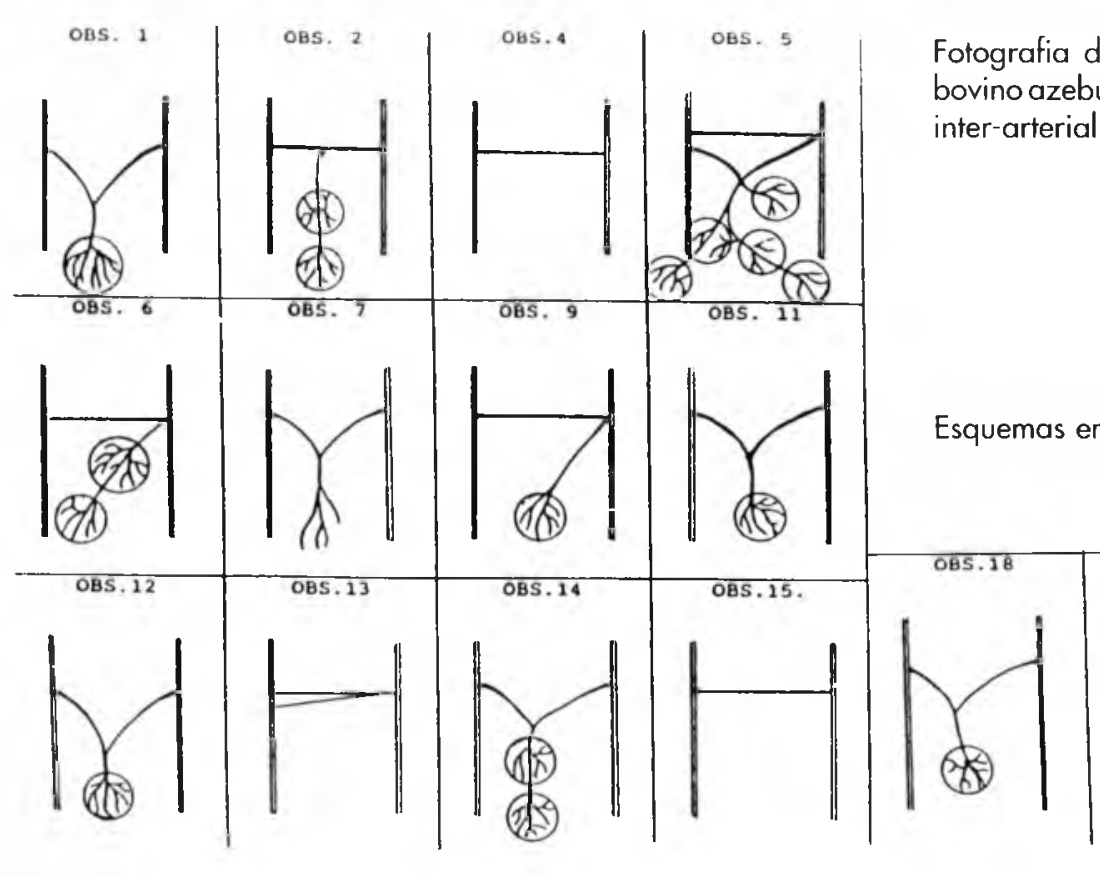

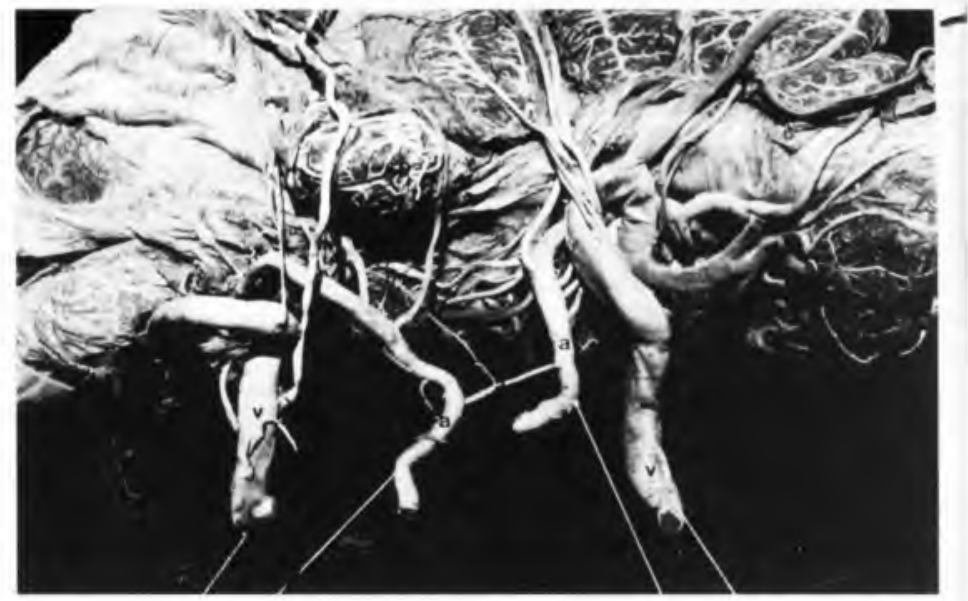

Figura 1

Fotografia da placenta de bovino azebuado mostrando os vasos do funículo umbilical, os quais, foram injetados com látex-Neoprene colorido e dissecados. As veias umbilicais (v) dispõem-se perifericamente e as artérias umbilicais (a), centralmente. Uma anastomose (a) interarterial transversal ocorre entre as artérias umbilicais. Um vaso cordona (c) origina-se na anastomose inter-arterial e dirija-se aos cotilédones placentários (cp)

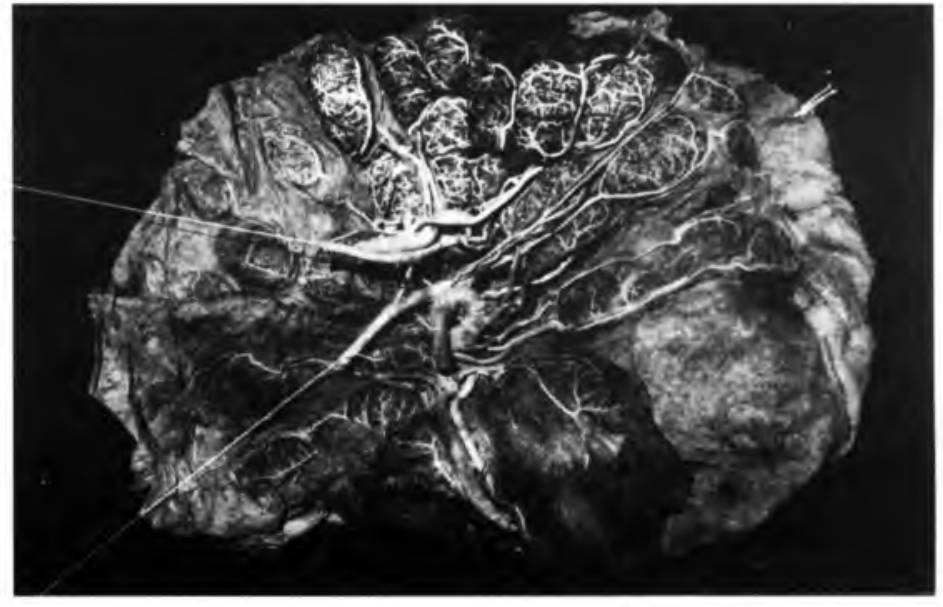

Figura 2

Fotografia de uma preparação correspondente a uma placenta de bovino azebuado, onde se nota, no funículo umbilical, uma anastomose inter-arterial oblíqua (a).

Figura 8

Esquemas em que foram verificadas anastomoses inter-arteriais 
III - PIACENTA

a) Cotilédonos

O formato dos cotilédones é variado, sendo que eles podem ser circulares, elipticos, quadrangulares, ovoides, reniformes e periformes (ligs. 5 e 6). Na maioria dos casos cles eram circulares erovódes. A medida que a gestaçăo progride há fusão do número de colilidones (lig. 0).

() numero de cotilidones for contado no total es separadamente no corno gestante e no corno nĩo-gestante. () número médio de cotilédones por placenta foi de 62,25 , sendo 46,25 no corno uterino gestante 16,15 no corno uterino não-gestante. () númcro máximo

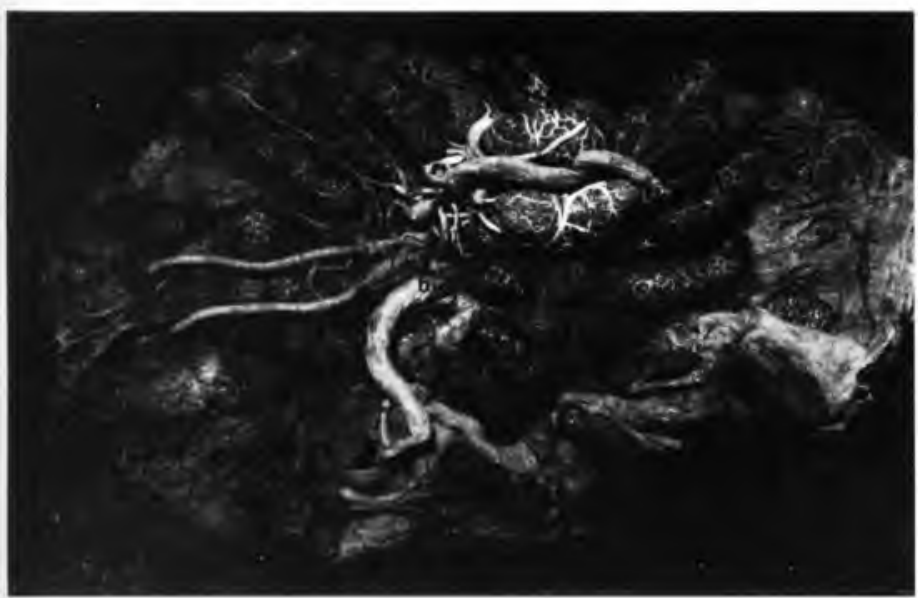

Figura 3

Fotografia da placenta de bovino azebuado evidenciando o hilo da placenta (h) e a área de implantação do funículo umbilical ou pedículo do funículo na superfície fetal da placenta.

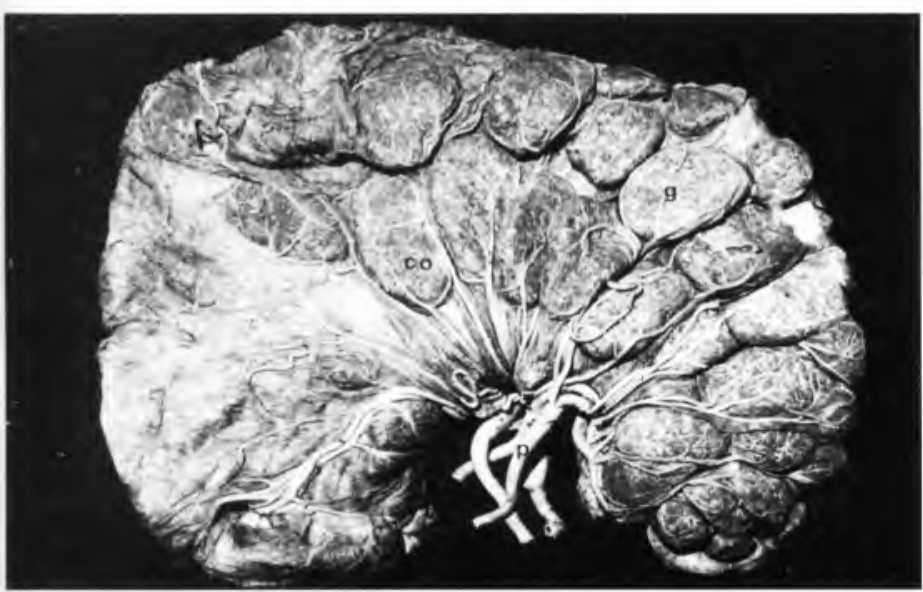

Figura 4

Fotografia da placenta de bovino azebuado, das duas fileiras de cotilédones (co) de um lado de implantação do pedículo umbilical ( $p$ ) Nota-se a presença de cotilédones grandes ( $g$ ) ao redor da implantação do pediculo $(p)$.

de cotiledones por placenta foi de 88 e o numero mínimo foi de 35. sendo 61 e 35 no colno tlterino gestante e 28 e 0 no corno tlerino nà()-gestanto

Notil-se que à medida que a gestação progride há fissão dos cotilédones (1).

(onsiderando agora o tamanho dos cotilédones, optamos por classificá-los em grandes (7 a 12 cm), médios (4 a $6.9 \mathrm{~cm}$ ) e pequenos $(2$ a $3.9 \mathrm{~cm})$.
() número médio de cotilédones grandes no corno uterino gestanté é de 3,25 è no corno não-gestante não aparecem cotilédones grandes. () número médio de cotilédones médios do corno ulerino gestante é de 33,6 e do corno uterino nào-gestante e de 0.75 . () número médio de cotiledones pequenos no corno uterino gestante é de 9,05 e no corno uterino naio-gestante é de 15.35. Portanto, no como ulerino gestante predominam os cotiledones médios e no corno ulerino não-gestante predominam os cortikdones pequenos.

b) Disposição geral dos vasos nos cotilédones

A artéria e a veia que se dirigem alo corno ulerino gestante

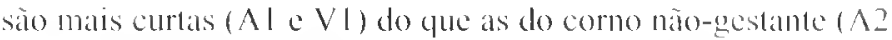
e V2). Lstas dispōem-se ao nivel do corno gestante, vascularizando parte deste corno; atravessam o corpo do útero e alingem o corno nào-gestante, após pereorrerem a curvalura menor dos conos uterinos (Fig. 7)

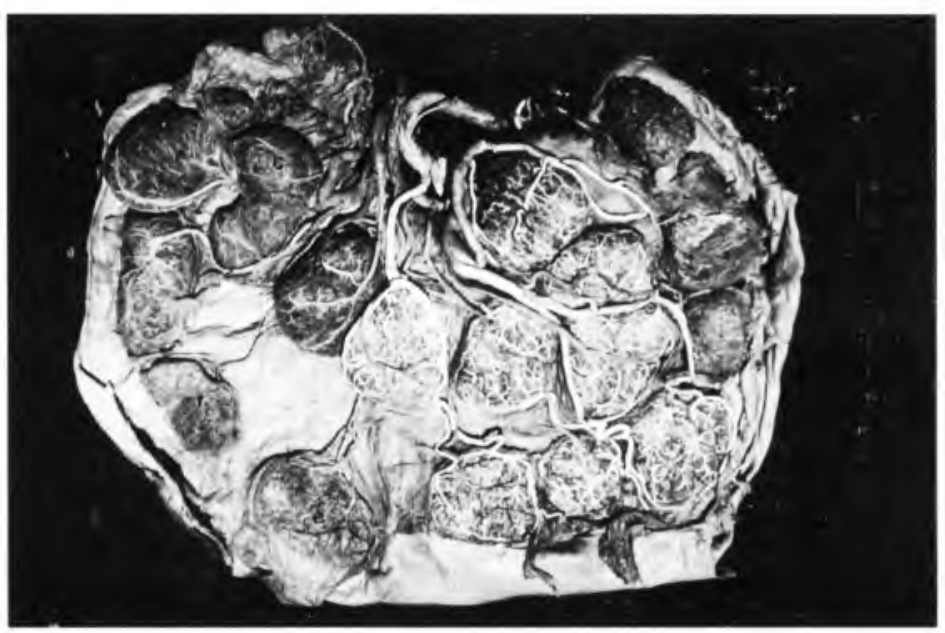

Figura 5

Fotografia da placenta de bovino azebuado, onde se vê o formato dos cotilédones do corno uterino gestante: circulares (c), elípticos (e), reniformes $(r)$ e ovóides (o).

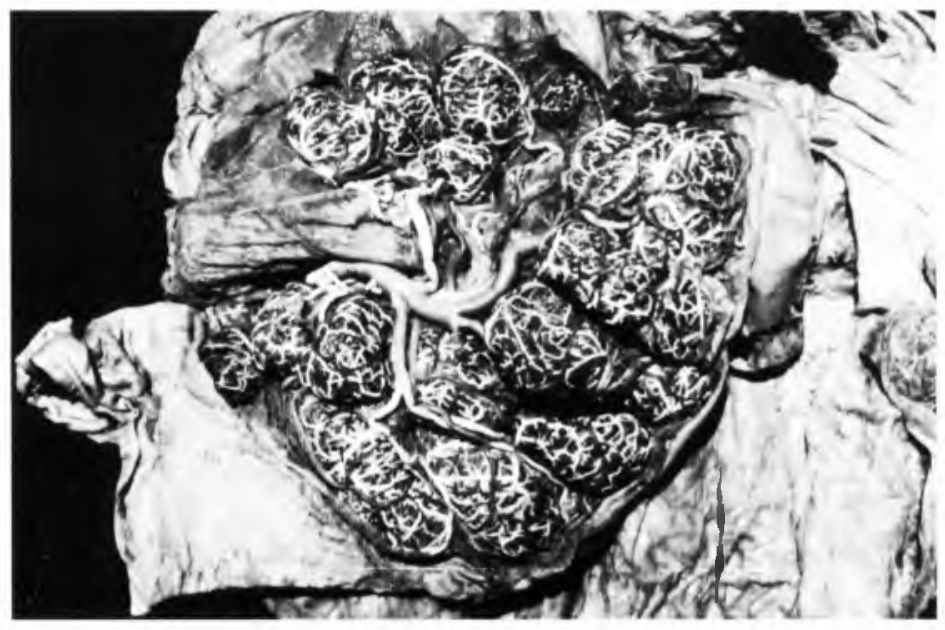

Figura 6

Fotografia da placenta de bovino mostrando o formato dos cotilédones do corno uterino não-gestante. Neste caso observam-se cotilédones quadrangulares $(q)$, ovóides $(0)$, piriformes $(p)$ e circulares $(c)$. 


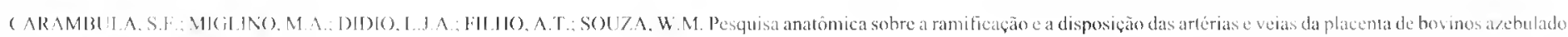

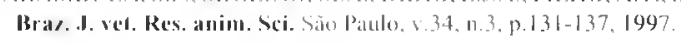

Tipos de distribuição vásculo-cotiledonária

()s tipos de distribuição vásculo-cotiledonar são, como o nome indica, os arranjos resultantes da relação entre vasos (arterials e venosos) e os cotiledones aos quais se dirigem ou dos quars provem. loram reconhecidos tipos arteriocotiledonários e venocotiledonários.

Diante da distribuiçâo destes tipos em cada corno uterino gestante e nào-gestante, evidenciamos, na Prancha 2 (fig. 9), os lipos mais liegüentes arteriocotiledonários e venocotiledonários. Ao nivel coliledonario, as anastomoses ocorrem tanto na distribução das artérias quanto ná das veias, além da anastomose mter-arterial an nirel do funiculo umbilical.

Notamos um grupo de cotiledones irrigado por uma artéria e drenados por multiplas veias. Em alguns casos havia arterias e veias que irrigavam ou drenavam cotilédones do corno uterino oposto (Pranchas 3 e 4) (Figs. 10 e 11 ).

\section{COMENTÁRIOS}

Segundo Montane; Bourdellet6 (1917), o funiculo umbilical dos ruminantes possui 2 artérias e 2 veias umbilicais. lisses vasos, de acordo com Panigel ${ }^{18}$ (1959), possuem trajeto

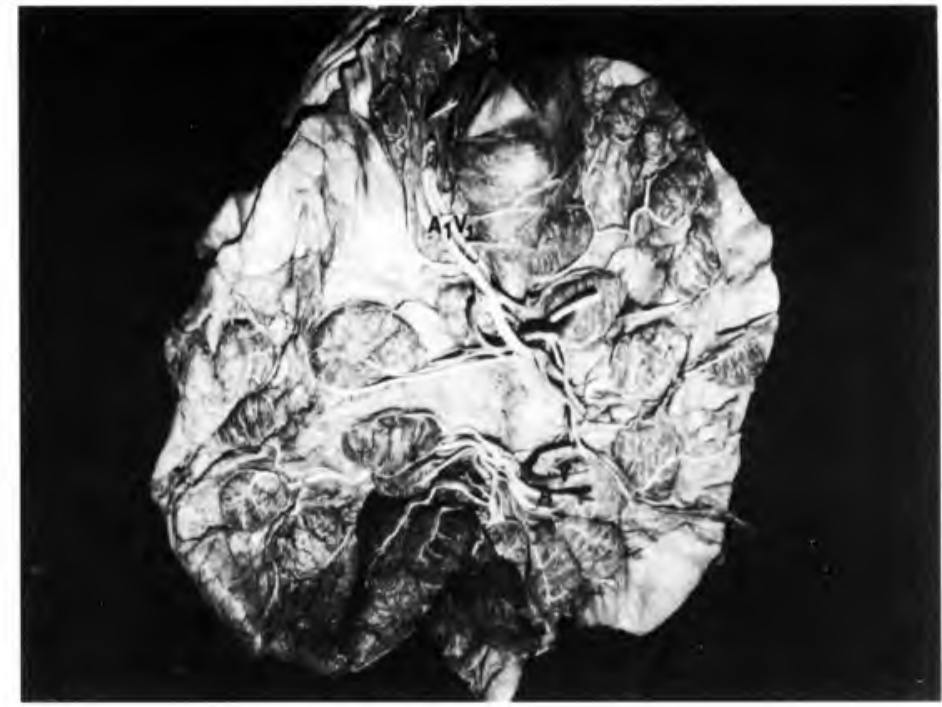

Figura 7

Fotografia dos vasos placentários onde se identificam: a artéria do corno uterino gestante (A 1), a artéria do corno uterino não-gestante (A2), a veia do corno uterino gestante (V1) e a veia do corno uterino não-gestante (V2). Neste caso devido à ausência de anastomose interarterial, notam-se dois territórios definidos de vascularização placentária.

\section{IIustraçâo dos tipos mais frequentes artćrio-cotilcdonários e veno-cotiledonários e nâo gestante TIPOS ARTERIOCOTILEDONARIOS CORNO UTERINO GESTANTE \\ TIPOS ARTERIOCOTILEDONARIOS CORNO UTERINO NAO GESTANTE}
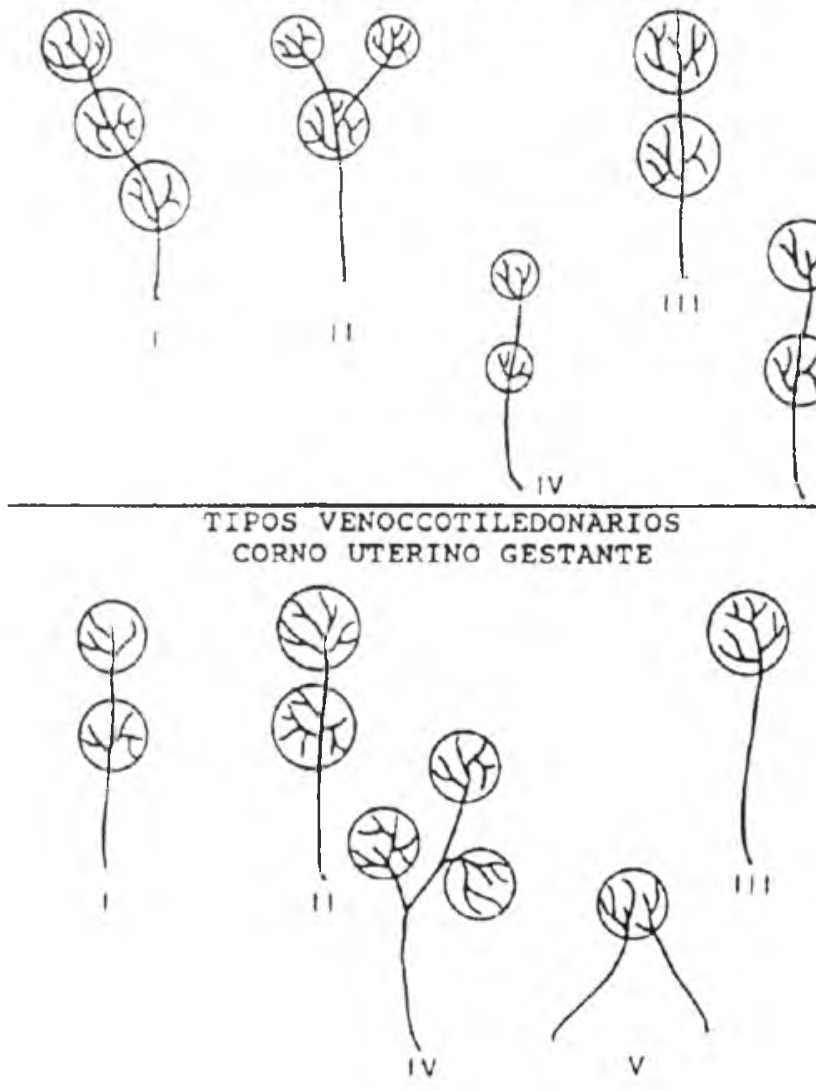
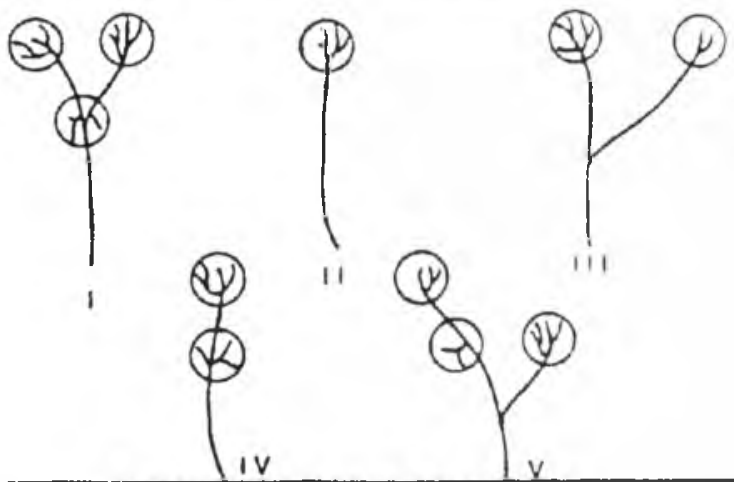

EDONARIOS CORNO UTERINO NAO GESTANTE
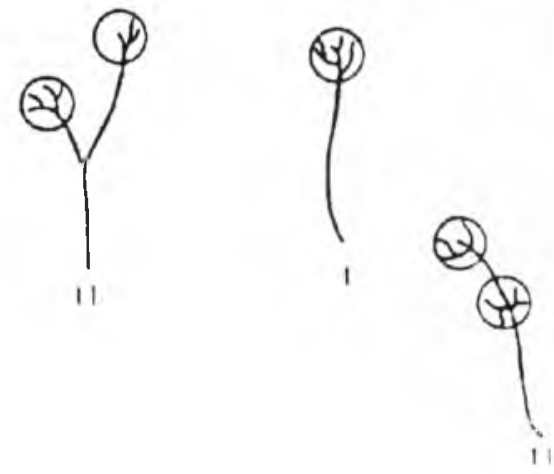

Figura 9

Ilustração dos tipos mais freqüentes artério-cotiledonários e veno-cotiledonários e não-gestante. 
paralcelo ao funiculo e dispoiem-se de modo a ter as artérias no centro e as veias na periferia, assim ilustradas por Leonardo, como se ve no livro de Kecle ${ }^{13}$ (1983). Fissa disposição (Barone2, 1976) foi considerada semelhante a dos ovinos por Pelagalli el al. ${ }^{19}$ (1973), Miglino15 (1991) e por nos em bovinos azebuados.

No funiculo umbilical as artérias apresentam uma anastomose proxima da placenta. claramente visivel no desenho feito por l.conardo (Kecele13, 1983). ce confirmada por Miglino's (1991). de acordo com Hyrtl' ${ }^{12}(1880)$, citado por Young 24 (1967). lisses autores a consideram em posiçào justaplacentária, o que foi confirmado na maioria dos casos estudados por Miglino ${ }^{15}(1991) \mathrm{c}$ por nos. Essa anastomose cra tida como constante nos rumi-nantes e no homem (Young2t. 1967), porém Bacsich, Boyd c Young ${ }^{3}$ (1961) consideram essa informaçào incorreta. De fato, pelo menos no Bos tumus (27.5\%) c no Bos indicus (75.5\%) esta comunicação nào é constante, o que demonstra a propriedade da assertativa da Bacsich el al: $:^{3}(|96|)$.

No Bos: Iaruru, de acordo com Miglino 15 (1991), a anastomose era mais freqüentemente única $(67,5 \%)$ do que dupla $(5.0 \%)$. Realmente esse dado é semelhante ao que encontramos. uma ve\% que nos bovinos azebuados uma anastomose dupla foi verilicada em apenas um caso $(5.0 \%)$.

Quanto à forma da anastomose, verilicamos sua disposição em " V" $\left(30,\left(0^{0} \%\right)\right.$, transversal $(30,0 \%)$, obliqual $(5,0 \%)$ c em " $(5.0 \%)$. Quando dupla cla se apresentava transversal e cm "V" $(5,0 \%)$. A disposiçào em "V" foi também encontrada em $15.0 \%$ dos casos por Miglino ${ }^{15}(1991)$ no Bos tammes, porém a dispo-sição transversal predominou sobre a obliqua $(52,5 \%$ para $5,0 \%)$.

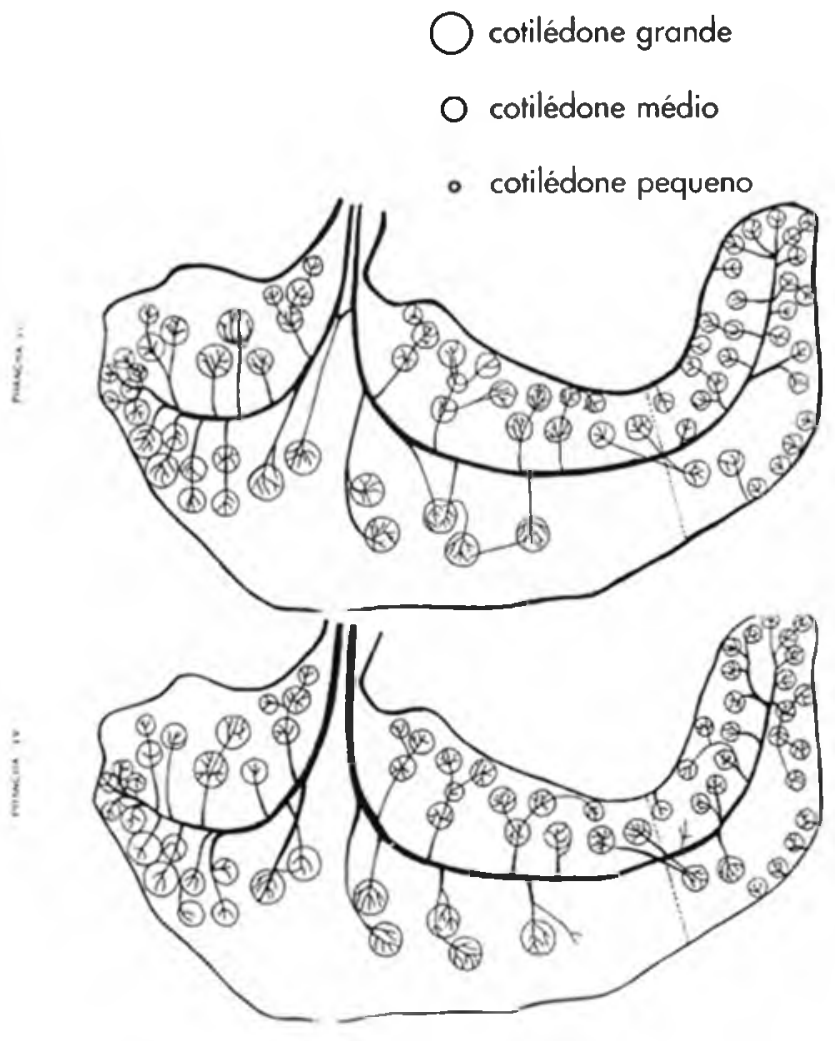

Figura 10 e 11

Disposição geral das artérias (Prancha 3, Fig. 10) e das veias (Prancha 4, Fig. 11) na placenta de bovinos azebuados. ()s ramos cordonais oriundos das anastomoses variaram de I (30. $10 \%$ dos casos) a $5(5.0 \%$ ). havendo $2 \mathrm{~cm} 7.5 \%$ no Bos fumrus: dos 15 casos onde ocorreram anastomoses, $12(60,0 \%)$ apresentaram vasos cordonais, e esses cram únicos em 10 observaçòs $(50.0 \%)$ c duplos em 2 casos $(10,0 \%)$. A maioria deles dirigia-se para os cotilédones ou scja a I $(30,0 \%), 2(15.0 \%)$ e $4(5.0 \%)$ cotiledones placentários, sendo portanto ramos cordonais cotiledonários. Somente num caso o ramo cordonal valscularizava a paraplacenta. Nos Bos raurus, estes ramos irrigavam cotilédones em $37.5 \%$ dos Casos, a paraplacenta $\mathrm{cm} 2.5 \%$ dos casos c ambos (ramos mistos) em $5,0 \%$ dos casos.

O hilo da placenta nào representa objeto de estudo especial em ruminantes.

Somente Miglino ${ }^{15}$ (1991) definiu a area de implantação do pediculo cordonal placentário, afirmando que o hilo apresentava de 10 a $12 \mathrm{~cm}$ de diâmetro. De acordo com a attora. ele ocupava posiçào eentral e sua área possuía menor número de cotilédones do que na imediata vizinhança em direçào à periferia. Já nos bovinos azebuados, apesar de a áreal hilar apresentar as mesmas dimensões, esta regiào mostrava-se rica em cotilédones, sendo que os maiores predominavam nesta zona, fato principalmente observado nas placentas retiradas de animais no linal da gestação.

A disposiçào de cotilédones na placenta não é inteiramente irregular. Já nos desenhos de l.conardo (Keele1.3. 1983) notam-se filciras de cotilédones, cujo arranjo lincar foi ilustrado na vaca por Fabricius 7 (1600), de acordo com Marshall/t (1952). Fistc autor lembrou que Hammond"l (1927) e Graig" (1930) confirmaram o arranjo lincar e descreveram 4 fileiras de cotilédones. Tambeim Björkman' (1954) referiu-sc aos dados de Hammond" ". Nas búfalas. as carunculas, segundo Haficz" (1954), cstavam dispostas em 4 ou 5 filciras e, nos mesmos animais, Abdel-Raouf; Badawil (1966) encontraram 4 fileiras e notaram que. as vezes, havia grupos de carúnculas isoladas e irregularmente distribuidas. Duas filcirats dorsais e duas fileiras ventrais de carunculas ao longo do comprimento dos comos uterinos foram descritas por Noden; 1)e Lahunta ${ }^{17}(1985)$ nos ruminantes. Nossos achados confirmam os de Miglino's (1991), onde os cotilédones estão dispostos em 4 fileiras, 2 de cada lado da implantação do pediculo umbilical no hilo da placenta.

O número de cotilédoncs nas placentas de bovinos arcbuados pode ser comparado vagamente com designaçós que permitem interpretar mais de um tipo de estrutura, ou com os cotilédones propriamente ditos. Nossos resultados indicam em media 02,25 cotilédones por placenta. sendo 46,25 no corno uterino gestante c 16.15 no corno uterino nào-gestante.

No Bos taurus, Miglimo 15 (1991) encontrou nas vacas Holstein 54 e 147 e nas Hereford 68 e 114 , sendo em média 88 por placenta.

Levando-se em contal as duas medias por placenta, verificase claramente uma diminuiçio da terça parte de cotilédones nos bovinos azebuados.

(utros autores encontraram 128 cotiledones por placenta, (Abdel-Raouf; Badawi', 1966), e 70) a 180 cotilédones (Björkman5". 1954).

() número de cotilédones do corno uterino gestante, segundo Rorik ${ }^{21}$ (1907), é sempre maior do que o do corno nào-gestante, o que foi confirmado por Bergmann 1 1922). Hammond ${ }^{11}$ (1927) e 
